\title{
Driving Mechanism of Cultivated Land Transition in Yantai Proper, Shandong Province, China
}

\author{
QIN Weishan ${ }^{1,2}$, ZHANG Yifeng ${ }^{1}$, LI Guangdong ${ }^{1}$ \\ (1. Institute of Geographic Sciences and Natural Resources Research, Chinese Academy of Sciences, Beijing 100101, China; 2. Geog- \\ raphy and Planning School of Ludong University, Yantai 264025, China)
}

\begin{abstract}
Cultivated land transition and its driving mechanism are the hotspots among studies on land use change. In this study, we constructed a framework to study the driving mechanism of cultivated land transition from the quantitative perspective. Based on the vector data of land use in 1990, 2000 and 2009 of Yantai Proper, Shandong Province China, 11 explanatory variables were chosen from two aspects: the elevation, slope, cost distance to major water area and cost distance to minor water area, which presented physical factors; cost distance to district center, cost distance to town center, cost distance to city expansion center, cost distance to major roads, cost distance to city roads, cost distance to county roads and cost distance to rural roads, which presented the socio-economic factors. Combined with spatial analysis tools and Logistic regression analysis model, we construct Logistic regression analyses with four objectives that were urban construction land, rural residential land, orchard and other lands. The results show that, cost distance to district center, cost distance to town center, cost distance to city expansion center and cost distance to city roads are the significant explanatory variables for the transition of cultivated land into urban construction land. The main explained factors on the transition of cultivated land into rural residential land are slope, cost distance to town center, cost distance to county roads and cost distance to rural roads. Slope, cost distance to minor water area, cost distance to town center, cost distance to county roads and cost distance to rural roads are the significant explanatory variables for the transition of cultivated land into orchard land. Elevation, slope, cost distance to major water area and cost distance to minor water area are the main explanatory variables on the transition of cultivated land into other land uses.
\end{abstract}

Keywords: cultivated land use transition; driving mechanism; Yantai Proper; China

Citation: Qin Weishan, Zhang Yifeng, Li Guangdong, 2015. Driving mechanism of cultivated land transition in Yantai Proper, Shandong Province, China. Chinese Geographical Science, 25(3): 337-349. doi: 10.1007/s11769-014-0712-3

\section{Introduction}

Land use/land cover change (LUCC) is an important part in the research of global environmental changes and sustainable development (Liu Jiyuan et al., 2009). Since the economic transformation, China's land use has been changing fast, and has shown significant regional variations on spatial patterns. Regional comparisons on processes, patterns and drivers, are considered as effective methods to reveal land use/cover changes on global and regional scales. Cultivated land use transition is an important part in urban and rural development and transformation. With rapid development of China's industrialization, urbanization, informationization and agricultural modernization, cultivated land resources in most regions are diminishing. Firstly, it is converted into urban construction land and rural residential land. Secondly, it is internally adjusted into gardens, woodland, meadows and land for water conservancy facilities. Thirdly, it is converted into grassland and unused land when left uncultivated and destructed. Cultivated land resources' shortage has been a restraint in China's sur-

Received date: 2014-01-10; accepted date: 2014-05-05

Foundation item: Under the auspices of National Natural Science Foundation of China (No. 41130748)

Corresponding author: ZHANG Yifeng. E-mail: zhangyf@igsnrr.ac.cn

(C) Science Press, Northeast Institute of Geography and Agroecology, CAS and Springer-Verlag Berlin Heidelberg 2015 
vival and development, so it will be of vital importance to make clear cultivated land changes and its spatial distribution variations (Zhang et al., 2003; Barbier et al., 2010; Long et al., 2010).

This phenomenon has attracted the attention of domestic and foreign scholars. They have mainly focused on spatial and temporal characteristics (Cai et al., 2009; He et al., 2009; Ye and Dong, 2011; Chi et al., 2013), influencing factors (Kong et al., 2003; Long et al., 2007; Chen et al., 2012; Gong et al., 2012; Yang et al., 2013) and driving mechanisms (Ding, 2003; Crk et al., 2009; Dong and Zang, 2011; Long et al., 2012; Cao et al., 2013) of cultivated land transition. Li et al. (2004) analyzed cultivated land changes and driving mechanisms of 13 northern provinces based on the data of the early 1980s, early 1990s, later 1990s and early 2000s.

Transfer matrix on land use change has been used on the change of land use spatial process in Shenzhen City (Shi et al., 2000). An integrated model which includes SD (system dynamics) model and CLUE-S (conversion of land use and its effects at small regional extent) model is established, and this model can explain the spatial performance of land use under the requirements of land resources (Liang et al., 2008). The multi-agent and cellular automata methods are used on the planning of sustainable use of land resources (Liu et al., 2006). And based on the grey prediction model, the multiobjective decision model, the cellular automata model and geographic information system technology, the land use change prediction model are established (Qiu and Chen, 2008). Xie and Li (2008) uses the logistic regression model to study driving mechanisms on cultivated land change, and $\mathrm{Yu}$ et al. (2013) proposes the CA model which has a higher data interpretation capability.

The process and mechanism of the transition of cultivated land into non-agricultural land and its relationship with economic growth (Qu et al., 2005; Liu Qing et al., 2009), labor force change (Liu and $\mathrm{Li}, 2010$ ) and food security ( $\mathrm{Yu}$ and $\mathrm{Lu}, 2006$ ) also attract close attention. As to the research on the influencing factors and driving mechanisms of cultivated land use transition, at the beginning, most researchers analyzed the impact on cultivated land use change brought by demographic, economic, policy, and resource exploiting factors (Chen et al., 2007; Song et al., 2012), and discussed its driving mechanisms from qualitative point of view. Other researchers also conducted research on cultivated land use change modeling and forecasting. Later on, there were many studies on human factors (Bai and Zhang, 2002; Yan et al., 2006; Guan and Wang, 2009) and further comprehensive studies on both natural and human factors (Mao et al., 2009) on land use change mainly through simple mathematical models of quantitative analysis by building index system to integrate economic and social factors. There was also the attempt of combining GIS spatial analysis and socio-economic factors to build driving models of construction land, cultivated land, and woodland changes respectively (Ma et al., 2012). Li et al. (2013) selected elevation, slope and distance factors to analyze quantitatively their influences on Beijing urban sprawl from 1972 to 2010.

Bohai Rim is another hot area besides Changjiang (Yangtze) River Delta and Zhujiang (Pearl) River Delta, as the land use there changes greatly and presents obvious spatial difference. Zhu et al. (2001a) conducted a preliminary study on land use spatial patterns and driving mechanisms of Bohai Rim from 1985 to 1995, and found that $30 \%$ of the total land had changed, among which the cultivated land was the main type. The main flows of cultivated land change are the grassland and forests, city residential construction land, orchard and water area. And the land management policy, residential land per capita growth, adjustment of the agricultural structure and urban expansion are the main driving mechanisms on cultivated land change (Zhu et al., 2001b).

Although many studies have been conducted on this field, there are still some problems to be resolved. The quantitative research on cultivated land use transition and its mechanisms has not yet undertaken that far. Few studies analyzed the mechanisms of cultivated land use transition quantitatively by combining natural, social and economic factors such as elevation, slope, distance to the district center, distance to major roads, etc. Given the above, this paper focuses on driving mechanisms of cultivated land use transition via quantitative methods and takes Yantai Proper as the case.

\section{Materials and Methods}

\subsection{Study area}

The study area in this paper refers to the municipal districts of Yantai, a narrowly defined scope of Yantai City, the administrative divisions of which are Zhifu, Laishan, Fushan, Muping districts and Development Zone (Fig. 1). 


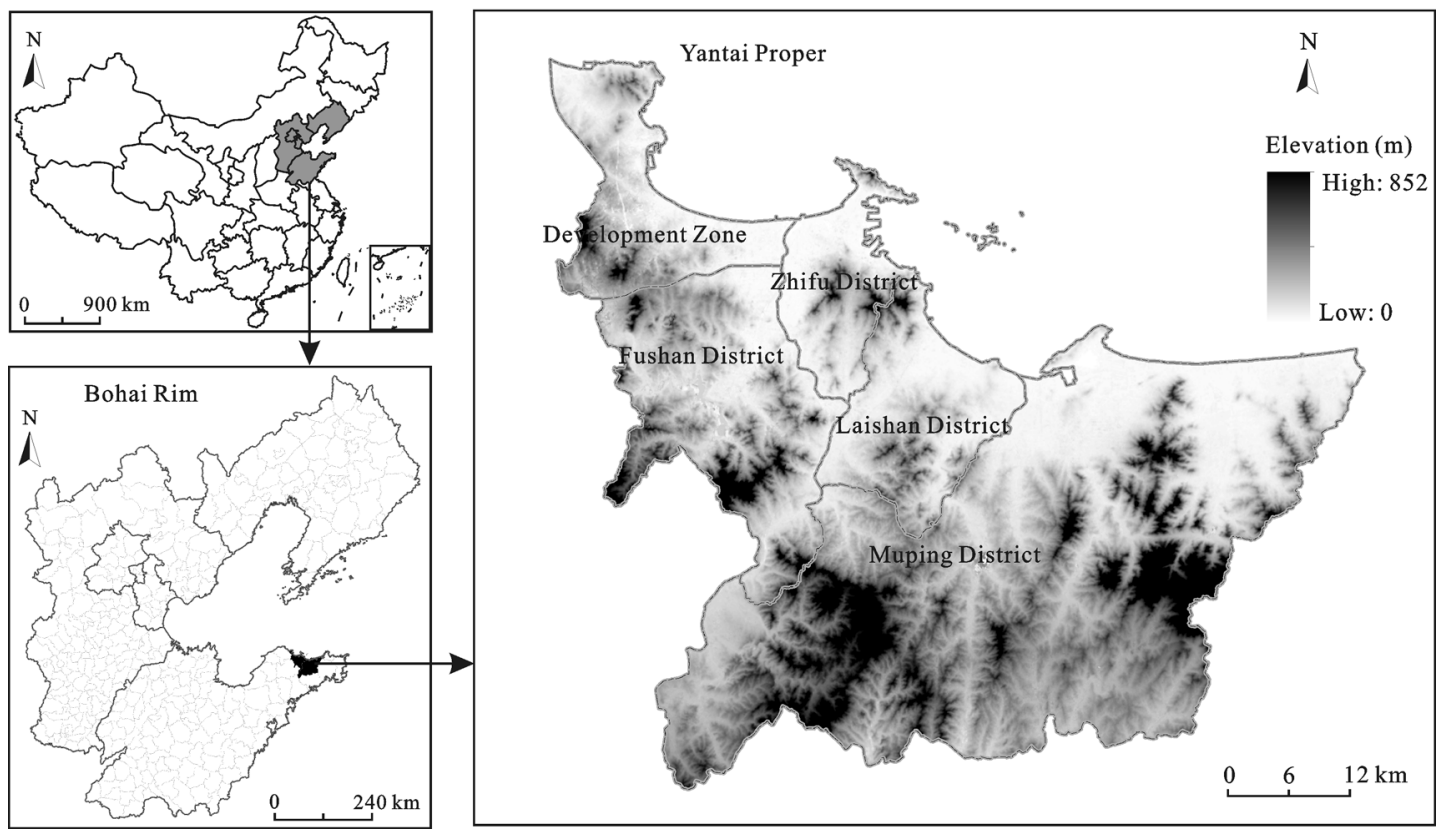

Fig. 1 Location of study area

This area is located in the northern coastal areas of Shandong Peninsula, with the latitude $37^{\circ} 04^{\prime}-37^{\circ} 38^{\prime} \mathrm{N}$ the longitude $121^{\circ} 15^{\prime}-121^{\circ} 56^{\prime} \mathrm{E}$, and is as large as $2722 \mathrm{~km}^{2}$. With gentle rolling hills and crisscrossed ravines, it is mostly hilly area. It presents many landforms such as low mountains, hills, quasi plains and coastal plains. The southern part is mountainous, the western part is relatively flat, and the northern part as the coastal zone is the Mountainous Harbor type coast with a tortuous shoreline. It is a typical city among Bohai Rim regions. Therefore, it is typically representative to take this area as the case to study Bohai Rim.

\subsection{Data processing}

Landsat TM data in 1990, 2000, and 2009 are used in the study. Before the image analysis, we carry out remote sensing image preprocessing, which includes remote sensing image radiometric correction, geometric correction, image cropping, image enhancement (contrast enhancement, color conversion, spatial filtering, principal component transforming), etc. The main purpose is to eliminate the image distortion, enhance the image quality, and obtain the same coordinate system for the images with different temporal and spatial projection in order to conduct the comparison and integration of different data. After being preprocessed in the ArcGIS 10.0, the images are interpreted visually into layers of land use type of Yantai Proper in the years of 1990, 2000 and 2009 (Fig. 2). Then, according to national land use classification criteria and the purpose of this study, the land use types can be divided into nine categories, namely urban construction land, rural residential land, cultivated land, orchard land, forest land, grassland, water area, other construction land and other land (bare land, beaches, etc.). The classification result is good with a kappa coefficient 0.82 through the verification test on land use map of 2009 by GPS.

Elevation (0-852 $\mathrm{m}$, five categories) and slope $\left(0^{\circ}-58^{\circ}\right.$, five categories) are generated by DEM data in ArcGIS 10.0. The road data of 2009 comes from National

Table 1 Data and its type

\begin{tabular}{cccl}
\hline Format & Year & Data & Remarks \\
\hline & $1990 / 6 / 2$ & TM & 30 m resolution (thermal infrared band 120 m resolution) \\
Raster & $2000 / 6 / 12$ & ETM + & 15 m resolution (thermal infrared band 60 m resolution) \\
& $2009 / 7 / 15$ & TM & 30 m resolution (thermal infrared band 120 m resolution) \\
Vector & 2009 & DEM & from NASA, 30 m resolution \\
\hline
\end{tabular}



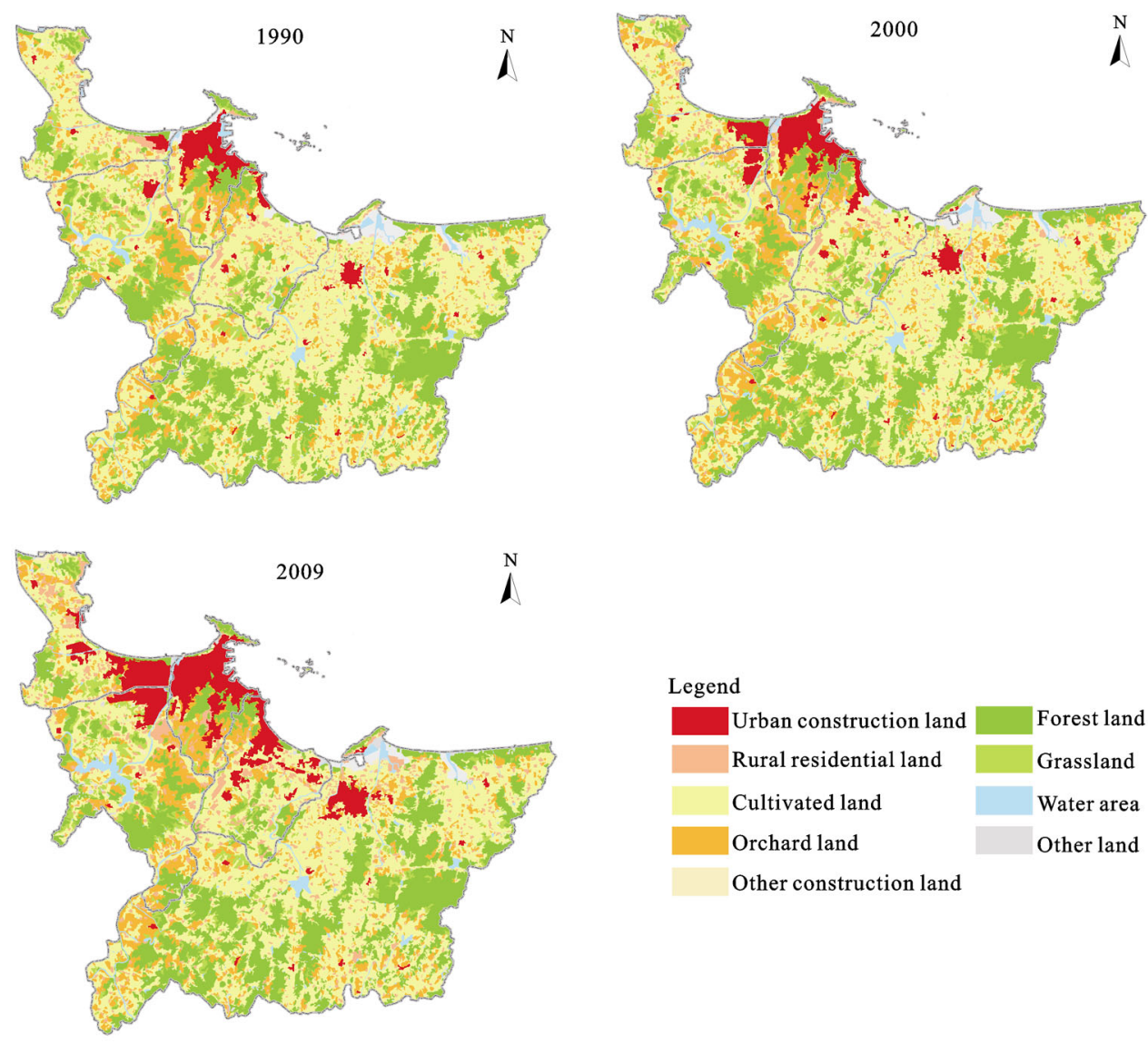

Fig. 2 Land use of Yantai Proper (1990, 2000 and 2009)

Road Traffic Data. The vector data of governmental residence comes from the basic geographic data provided by National Geometrics Center (Table 1, Fig. 3).

\subsection{Binary logistic regression}

Binary logistic regression is applied to investigate the effects of selected variables on the probability of cultivated land transition. The logistic regression model is formed as:

$\log \left(\frac{y}{1-y}\right)=\beta_{0}+\sum_{i=1}^{n} \beta_{i} x_{i}+\varepsilon$

where $y$ is the probability of cultivated land transition; $\beta_{0}$ is the intercept; $\beta_{i}$ is a vector of estimated parameter $i ; x_{i}$ is a vector of driving factor $i$; and $\varepsilon$ is a randomly distributed residual error.

One logistic regression model is built for each type which the cultivated land converts to. The dependent variable is a binary vector coded as 1 (changed) or 0 (no change). The explanatory variables are the six factors to be described in Section 2.4.

The Percent Correct Predictions (PCP) is calculated to evaluate the performance of the logistic regression model. The samples are classified into predicted $0 \mathrm{~s}$ and $1 \mathrm{~s}$ based on the built model, and then they are compared with the actual 0s and 1s. Finally, the (total) PCP is calculated as the number of correctly predicted cases divided from the total number of cases. In addition, the percentage of correctly predicted area under the curve (AUC) of the relative operating characteristic (ROC) is calculated (Crk et al., 2009). The ROC curve is plotted with the sensitivity (true positive rate) versus the specificity (false positive rate) for every possible cutoff that can be chosen to convert the predicted probability of cultivated land transition into the actual degree of the cultivated land converted. The AUC is then calculated as a measure of the probability of the model to render a higher predicted value of cultivated land converted for a pixel that undergoes transition than for those that does not. An AUC value approaching 1 indicates perfect performance of the model. Nagelkerke's $R^{2}$ is used to evaluate the model's fit (Betts et al., 2006). Nagelkerke's $R^{2}$ is calculated via the following equation: 

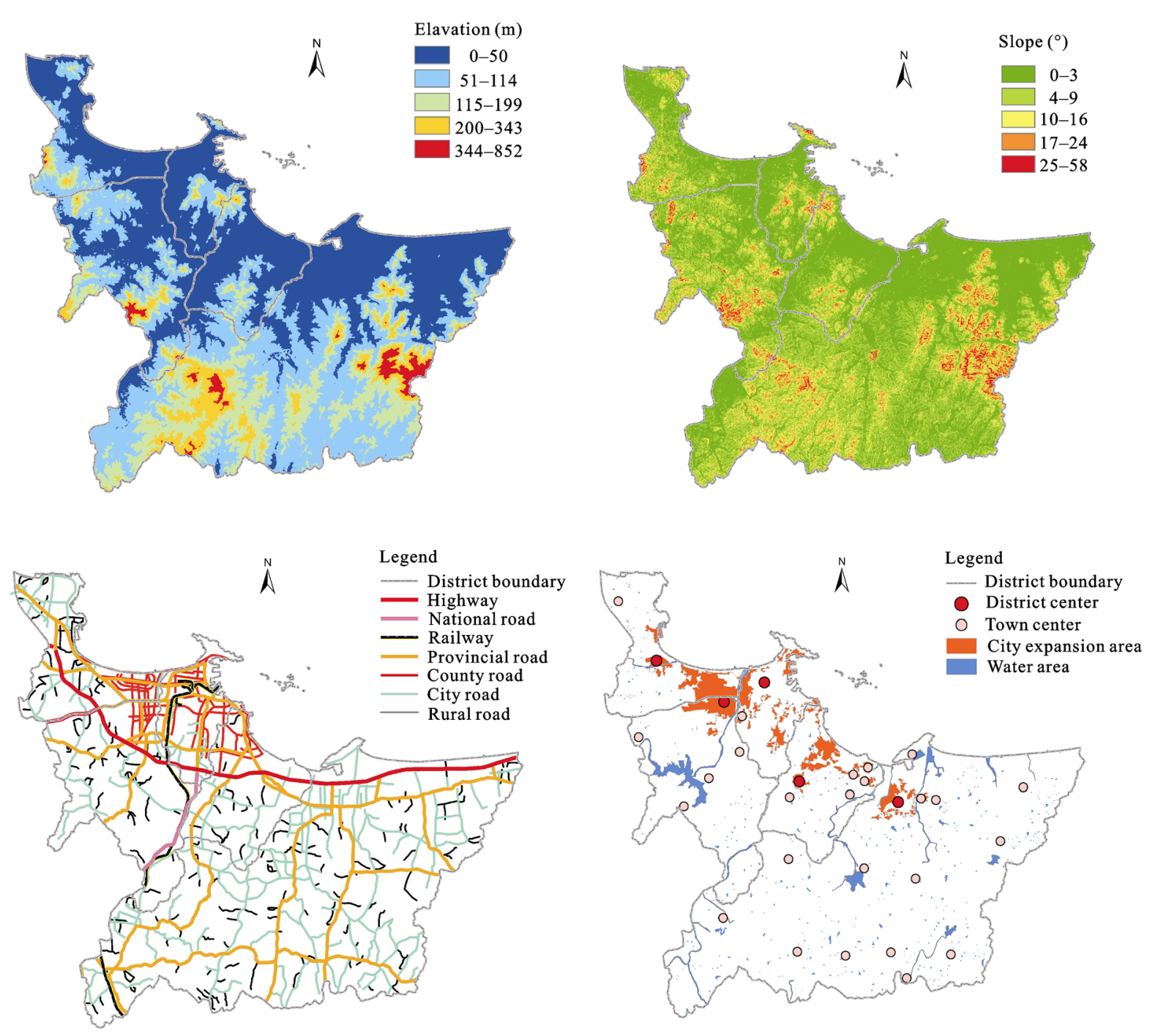

Fig. 3 Schematic plot of basic data

$R^{2}=1-\exp \left[-2 / n\left(l_{\mathrm{A}}-l_{0}\right)\right]$

where $n$ is the sample size; $l_{\mathrm{A}}$ is the log-likelihood of the focused model; and $l_{0}$ is the log-likelihood of the null model with only the intercept as a predictor. The calculated $R^{2}$ is consistent with the classical $R^{2}$ and can be interpreted as the proportion of explained variation (Betts et al., 2006). In addition, Moran's $I$ of the residual of the models is calculated to check the spatial autocorrelation of the residuals of the models via GeoDa.

\subsection{Variables}

There are many factors influencing cultivated land transition, and these factors can be divided into two categories: natural factors and socio-economic factors. The natural factors include topography, landform, hydrology and other factors; there are many factors in socioeconomic category, such as the level of economic development, per capita income of farmers, urbanization level, road network density and so on. In this study, we only choose 11 factors that can be quantified to patches of the land use.

\subsubsection{Natural factors}

In this paper we take four factors that can be quantified to represent natural factors:

(1) Elevation: elevation is derived from the $30 \mathrm{~m}$ resolution DEM and the range is $0-852 \mathrm{~m}$.

(2) Slope: slope was also derived from the $30 \mathrm{~m}$ resolution DEM and the range is $0-90^{\circ}$.

(3) Cost distance to major water area: major water areas are the big water area such as the rivers and the lakes. 
(4) Cost distance to the minor water area: minor water areas are the small water area such as the ponds.

\subsubsection{Socio-economic factors}

In this paper we take seven factors that can be quantified to represent socio-economic factors:

(1) Cost distance to district center: We select five Center City Districts (Zhifu District, Laishan District, Muping District, Fushan District and Development Zone) as one of the important factors. Generally speaking, it will be easier for the transition of cultivated land to urban construction land if it is closer to the district center. And also, with the development of urban agriculture, the closer to the district center it is, the easier for the transition of cultivated land to orchard land it will be.

(2) Cost distance to town center: We choose the township located in the five districts of Yantai as one of the study factors. The closer to the town center it is, the easier for the transition of cultivated land to orchard and rural residential land it will be.

(3) Cost distance to city expansion center: We took overlay analysis of the Urban Development Planning of Yantai City (2005-2020) and Land Use Planning of Yantai City (2006-2020) to extract the range of urban expansion boundary and expansion center of Yantai City.

(4) Cost distance to major roads: Because there is only one railway, one highway and one national road that cross the studied area, we combine the three roads with provincial roads as one explanatory variable. Distance difference to major roads will play an important role in the transition of cultivated land.

(5) Cost distance to city roads: City roads are built mainly for the city downtown traffic and pedestrians, and connecting the burden of external traffic.

(6) Cost distance to county roads: County roads are the roads which connect the counties (and districts) and the main township road. County roads have a good connectivity and accessibility.

(7) Cost distance to rural roads: The rural roads are the main transportation systems in the rural area.

In this study, we use the cost of distance measurement under spatial analysis tools of ArcGIS 10.0 to quantify the explanatory variables above (Figs. 4-5). First, we take the gridded processing to the data of land use in 2009 , the $30 \mathrm{~m} \times 30 \mathrm{~m}$ grids were formed, and then calculate the cost distance of each grid to the influencing factors.

\section{Results and Analyese}

\subsection{Spatial and temporal analysis of cultivated land transition}

From 1990 to 2009 , a total of $136.71 \mathrm{~km}^{2}$ of cultivated land has converted to construction land, accounting for $60.22 \%$ of the total transition. And $46.07 \mathrm{~km}^{2}$ has been converted from 1990 to $2000,90.64 \mathrm{~km}^{2}$ has been converted from 2000 to 2009 . During the twenty years, a total of $73.32 \mathrm{~km}^{2}$ cultivated land has converted to urban construction land; at the same time, about $57.64 \mathrm{~km}^{2}$ cultivated land has converted to rural residential land, and about $5.75 \mathrm{~km}^{2}$ cultivated land has converted to other construction land (Table 2).

From 1990 to 2009 , a total of $68.83 \mathrm{~km}^{2}$ of cultivated land has converted to orchard, forest land and grassland, accounting for $30.32 \%$ of the total transition of cultivated land. And $46.99 \mathrm{~km}^{2}$ has been converted from 1990 to 2000 , while $21.84 \mathrm{~km}^{2}$ has been converted from 2000 to 2009 , which means the rate of the transition from cultivated land to the orchard, forest land and grassland has decelerated. During the twenty years, a total of $57.59 \mathrm{~km}^{2}$ cultivated land has converted to orchard. At the same time, about $9.88 \mathrm{~km}^{2}$ cultivated land has converted to forest land, and only a little about 1.36 $\mathrm{km}^{2}$ has converted to other agricultural land, like grassland. We can see that most of the cultivated land has converted to orchard land within the structure of agricultural land. And about $21.47 \mathrm{~km}^{2}$ cultivated land has converted to water area and other land use types from 1990 to 2009 , accounting for $9.46 \%$ of the total cultivated land transition.

We can see from Table 3 that the converted cultivated land focuses in Muping District, Fushan District and Development Zone of Yantai, while that in Zhifu District and Laishan District is relatively less. And the main directions of the cultivated land transition are orchard and rural residential land in Muping District, which is mainly because Muping is the main source of the agricultural and sideline products in Yantai, and urban agriculture has developed rapidly in Muping in the last twenty years. The main direction of cultivated land transition is urban construction land in Fushan District and Development Zone. This is mainly because Fushan District and Development Zone are the areas for industrial transformation and westward expansion of the district center.

A total of $16.19 \mathrm{~km}^{2}$ cultivated land has converted 

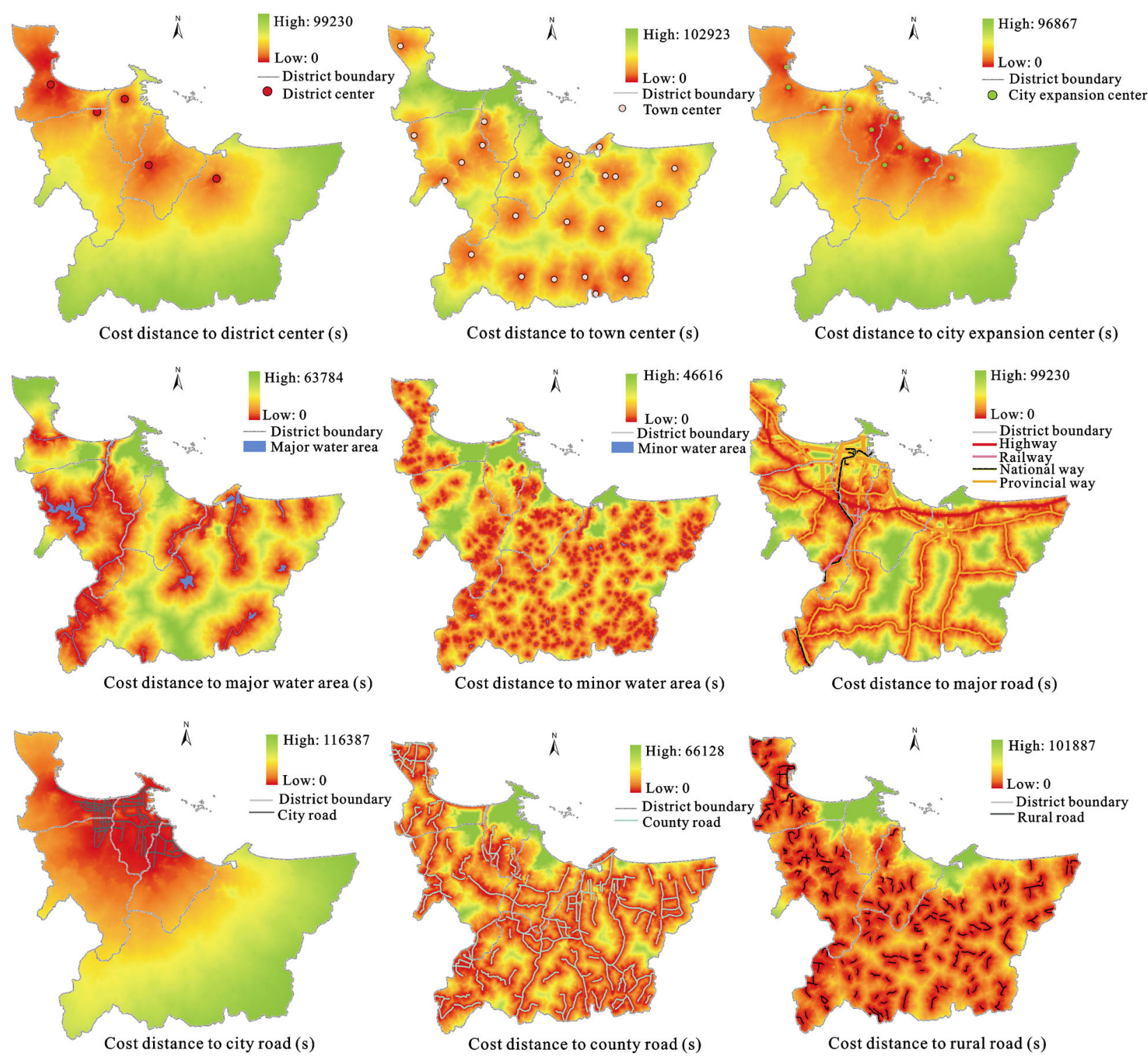

Fig. 4 Cost distance of all land use types (1990-2009)

Table 2 Statistics of cultivated land transition in Yantai Proper from 1990 to $2009\left(\mathrm{~km}^{2}\right)$

\begin{tabular}{ccccccccc}
\hline Period & Urban construction land & Rural residential land & Other construction land & Orchard & Forest land & Grassland & Water area & Other land \\
\hline $1990-2000$ & 23.48 & 22.43 & 0.16 & 38.78 & 7.31 & 0.90 & 14.74 & 2.48 \\
$2000-2009$ & 49.84 & 35.21 & 5.59 & 18.81 & 2.57 & 0.46 & 3.55 & 0.70 \\
$1990-2009$ & 73.32 & 57.64 & 5.75 & 57.59 & 9.88 & 1.36 & 18.29 & 3.18 \\
\hline
\end{tabular}

to urban construction land during the last twenty years in Fushan District, and the area of Development Zone is $24.02 \mathrm{~km}^{2}$. Industrial park construction and city expansion in Laishan District also took up a lot of cultivated land, and about $15.10 \mathrm{~km}^{2}$ cultivated land has converted to urban construction land during the last twenty years. A total of $20.66 \mathrm{~km}^{2}$ cultivated land has converted to rural residential land, while $23.56 \mathrm{~km}^{2}$ cultivated land has converted to orchard land in the last twenty years in Muping District. About $12.59 \mathrm{~km}^{2}$ and $11.18 \mathrm{~km}^{2}$ cultivated land has both converted to orchard land in Zhifu District and Fushan District.

\subsection{Quantitative analysis of mechanisms of culti- vated land transition}

Logistic regression models with eleven selected vari- 
ables effectively explain the variance for all four types in cultivated land transition, i.e., urban construction land, rural residential land, orchard land and other lands. Here, other lands include five land use types, i.e., other construction land, forest land, water area, grassland and other land. The values of PCP from the highest

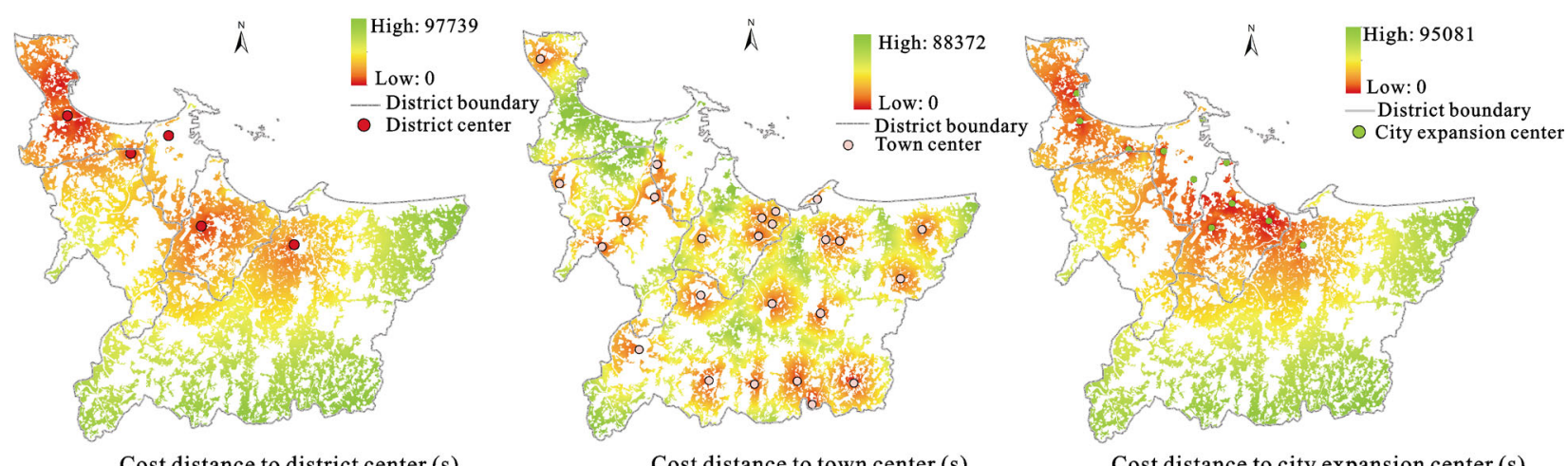

Cost distance to district center (s)

Cost distance to town center (s)

Cost distance to city expansion center (s)
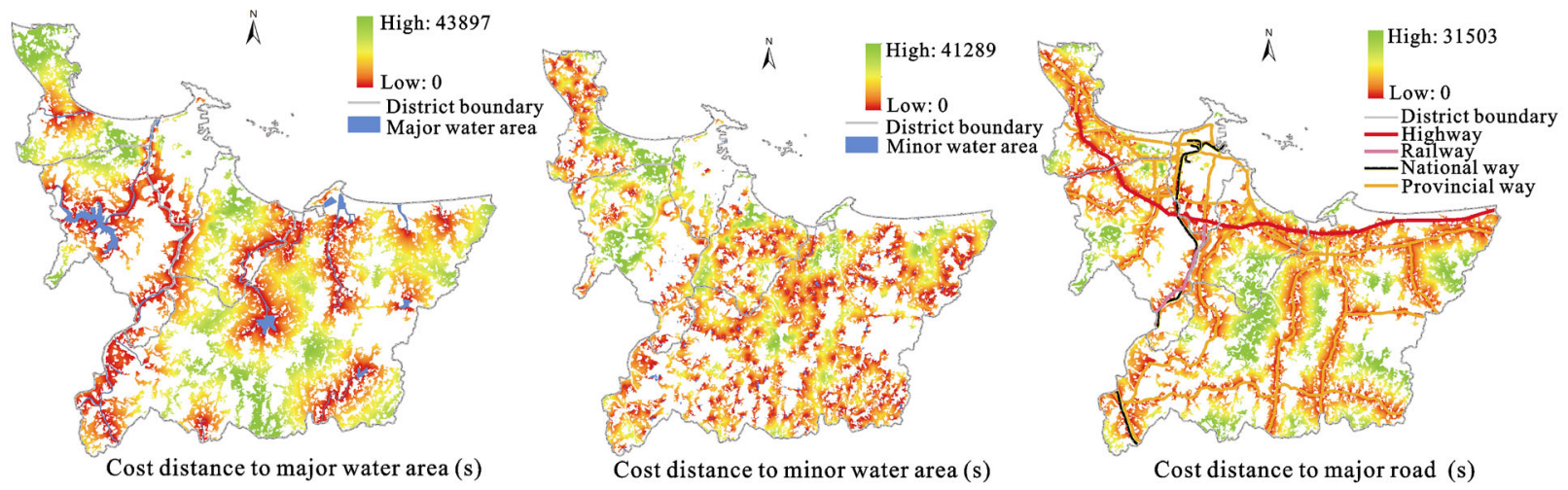

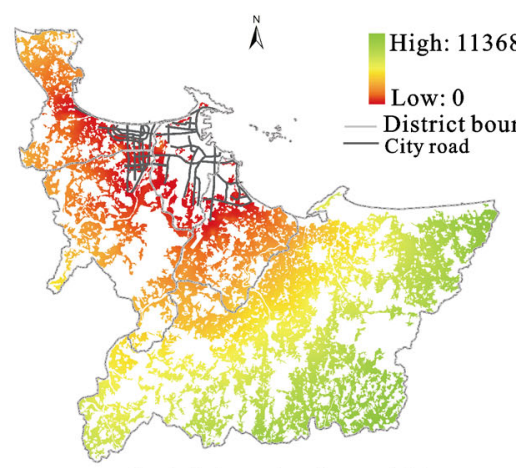

Cost distance to city road (s)

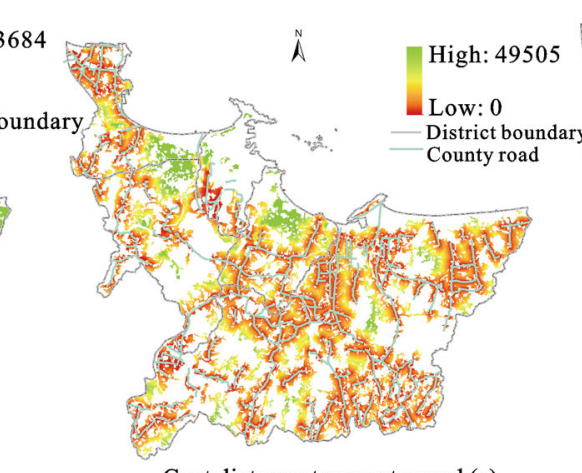

Cost distance to county road (s)

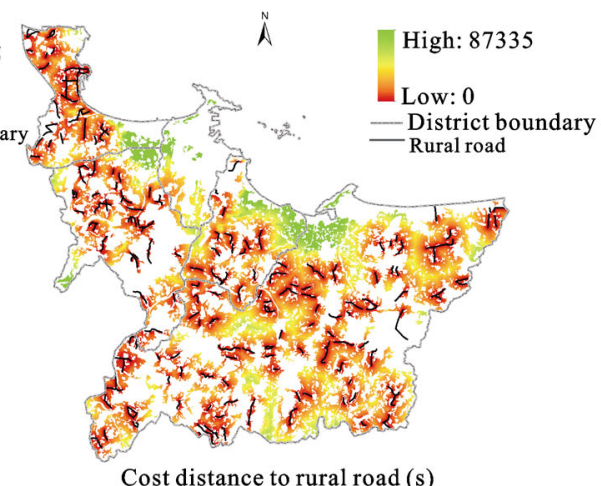

Cost distance to rural road (s)

Fig. 5 Cost distance of cultivated land transition (1990-2009)

Table 3 Partition statistics of cultivated land transition from1990 to 2009 in Yantai Proper $\left(\mathrm{km}^{2}\right)$

\begin{tabular}{|c|c|c|c|c|c|c|c|c|c|}
\hline District & $\begin{array}{l}\text { Urban construction } \\
\text { land }\end{array}$ & $\begin{array}{l}\text { Rural residential } \\
\text { land }\end{array}$ & $\begin{array}{c}\text { Other construction } \\
\text { land }\end{array}$ & Orchard & $\begin{array}{c}\text { Forest } \\
\text { land }\end{array}$ & Grassland & $\begin{array}{c}\text { Water } \\
\text { area }\end{array}$ & $\begin{array}{l}\text { Other } \\
\text { land }\end{array}$ & $\begin{array}{c}\text { Total } \\
\text { transition }\end{array}$ \\
\hline Zhifu District & 10.37 & 2.87 & 0.22 & 12.59 & 0.38 & 0.00 & 0.40 & 0.53 & 27.36 \\
\hline Laishan District & 15.10 & 9.23 & 0.81 & 3.76 & 1.66 & 0.00 & 3.26 & 0.16 & 33.98 \\
\hline Fushan District & 16.19 & 13.01 & 1.44 & 11.18 & 0.23 & 0.19 & 7.80 & 1.49 & 51.53 \\
\hline Development Zone & 24.02 & 11.87 & 2.49 & 6.50 & 0.44 & 0.12 & 0.64 & 0.51 & 46.59 \\
\hline Muping District & 7.64 & 20.66 & 0.79 & 23.56 & 7.17 & 1.05 & 6.19 & 0.49 & 67.55 \\
\hline Total Transition & 73.32 & 57.64 & 5.75 & 57.59 & 9.88 & 1.36 & 18.29 & 3.18 & 227.01 \\
\hline
\end{tabular}


to the lowest are $82.60,80.50,78.20$, and 75.40 for the types converted to rural residential land, orchard land, urban construction land and other land respectively (Table 4). The values under the ROC curves are $0.83,0.89$, 0.87 , and 0.78 for the four transition types respectively (Table 4), indicating a high degree of spatial consistency between the model predictions and actual cultivated land transition. Similar to the AUC, the explained variance of the probability of cultivated land transition for the type converted to rural residential land is the highest (52\%), followed by the types converted to orchard land, urban construction land and other land, with values of $49 \%, 47 \%$, and $41 \%$ respectively (Table 4 ).

The elevation factor has a significant influence on the transition of cultivated land into other land use types. It has an ordinary effect on the transition of cultivated land into rural residential land and orchard land. The slope factor plays an important role in the transition of cultivated land into rural residential land, orchard land and other land use types. .

Factor of cost distance to major water area (lakes and rivers) has a positively significant correlation on the transition of cultivated land into other land use types and has an ordinary effect on the transition of cultivated land into urban construction land. Factor of cost distance to minor water area (ponds and other minor water area) has a significant correlation on the transition of cultivated land into orchard land and other land use types, and has an ordinary effect on the transition of cultivated land into rural residential land.

Factors of cost distance to district center and city expansion center have a significant influence on the transition of cultivated land into urban construction land. Factor of cost distance to town center has a significant influence on the transition of cultivated land into urban construction land, rural residential land and orchard land.

Factor of cost distance to the major roads has an ordinary influence on the transition of cultivated land into urban construction land. Factor of cost distance to the city roads has a significant influence on the transition of cultivated land into urban construction land. Factors of cost distances to county roads and rural roads have significant influences on the transition of cultivated land into rural residential land and orchard land, and have an ordinary effect on the transition of cultivated land into other land use types.

Table 4 Summary of logistic regression models

\begin{tabular}{|c|c|c|c|c|}
\hline Variables & $\begin{array}{l}\text { Transition into urban } \\
\text { construction land }\end{array}$ & $\begin{array}{l}\text { Transition into rural } \\
\text { residential land }\end{array}$ & $\begin{array}{l}\text { Transition into } \\
\text { orchard land }\end{array}$ & $\begin{array}{c}\text { Transition into } \\
\text { other lands }\end{array}$ \\
\hline Constant & 7.211 & $-5.36^{* *}$ & $5.113^{*}$ & -1.928 \\
\hline Elevation & -0.152 & $0.096^{*}$ & $0.071^{*}$ & $0.202^{* *}$ \\
\hline Slope & -0.266 & $-0.461^{* *}$ & $0.377^{* *}$ & $0.444^{* *}$ \\
\hline Cost Distance to major water & $1.676^{*}$ & 0.243 & -0.001 & $-0.461^{* *}$ \\
\hline Cost distance to minor water & 0.684 & $-0.634^{*}$ & $-0.480^{* *}$ & $-0.874^{* *}$ \\
\hline Cost distance to district center & $-2.301^{* *}$ & -0.082 & 0.833 & -0.397 \\
\hline Cost distance to town center & $-1.059^{* *}$ & $-0.221^{* *}$ & $-0.208^{* *}$ & -0.028 \\
\hline Cost distance to city expansion center & $-1.268^{* *}$ & -0.113 & -0.886 & 0.642 \\
\hline Cost distance to major road & $-0.241^{*}$ & 0.153 & -0.066 & -0.060 \\
\hline Cost distance to city road & $-0.847^{* *}$ & 0.160 & 0.143 & -0.010 \\
\hline Cost distance county road & 0.932 & $-0.428^{* *}$ & $-0.451^{* *}$ & $0.628^{*}$ \\
\hline Cost distance to rural road & 0.843 & $-0.614^{* *}$ & $-0.326^{* *}$ & $0.569^{*}$ \\
\hline McFadden R-squared & 0.09 & 0.06 & 0.04 & 0.12 \\
\hline PCP & 78.20 & 82.60 & 80.50 & 75.40 \\
\hline AUC & 0.83 & 0.89 & 0.87 & 0.78 \\
\hline Log Likelihood & -193.65 & -1102.36 & -809.85 & -725.03 \\
\hline$R^{2}$ & 0.47 & 0.52 & 0.49 & 0.41 \\
\hline Prob (LR Statistic) & 0 & 0 & 0 & 0 \\
\hline
\end{tabular}

Note: *, ** denote that correlation are significant at $0.05,0.01$ levels respectively; PCP, precinct predictions; AUC, percentage of correctly predicted area under curve 
(1) Transition of cultivated land into urban construction land

Based on the results of Logistic analysis, cost distance to district center, cost distance to town center, cost distance to city expansion center and cost distance to city roads are the significant explanatory variables for the transition of cultivated land into urban construction land. Regression coefficients of all these factors are negative, respectively $-2.301,-1.059,-1.268$ and -0.847 . The nearer to the district center and town center it is, the easier the transition of cultivated land into urban construction land it is. Due to the radiating and driving of the city expansion, the urban peripheral area is the first place for urban outward expansion. City expansion is always along the city road, therefore the closer to the city roads, the easier for the transition of cultivated land into the city construction land.

The cost distances to major roads and to major water areas have an ordinary effect on the transition of cultivated land into urban construction land. The areas along major roads are mainly for urban expansion and economic activities. Therefore, traffic is one of the important factors for cultivated land transition. The regression coefficient of the cost distance to the major water area is positive (1.676), which means the farther to major water area it is, the easier for the transition of cultivated land into urban construction land it is. Because of the geological, geomorphologic and ecological conservation requirements, the transition of cultivated land into urban construction land will be forbidden.

(2) Transition of cultivated land into rural residential land

The main explained factors on the transition of cultivated land into rural residential land are slope, cost distance to town center, cost distance to county roads and cost distance to rural roads. The regression coefficient of the slope is negative $(-0.461)$. As the slope decreases, the transition of cultivated land into rural residential land will be easier. Cost distance to town center shows a negative effect $(-0.221)$, which means that the nearer to town center, the greater of the probability that the cultivated land is converted to rural residential land it will be. The peripheral regions of town center are highly gathered with population and economy, so rural residential land in these regions is expanding very fast resulting from the cultivated land transition.

The regression coefficients of cost distance to county roads and cost distance to rural roads are also negative, respectively -0.428 and -0.614 . Rural residential land expansion is mostly along the low grade road like the county, town and rural roads. Therefore, the nearer to county roads and rural roads it is, the easier for the transition of cultivated land into rural residential land it will be.

Elevation and cost distance to minor water areas are the ordinary factors to the transition of cultivated land to rural residential land. The district center area of Yantai has a low surrounding elevation, and the cultivated land that converted to rural residential land mainly lies in the outskirts of the city with a higher elevation than the district center. Rural residential land is always close to the pond, convenient nearby water.

(3) Transition of cultivated land into orchard land

Slope (0.377), cost distance to minor water area $(-0.480)$, cost distance to town center $(-0.208)$, cost distance to county roads $(-0.451)$ and cost distance to rural roads $(-0.326)$ are the significant explanatory variables for the transition of cultivated land into orchard land. The elevation factor has an ordinary effect on the transition of cultivated land into orchard land.

The regression coefficients of slope and elevation are positive, which means that with the increase of the gradient and elevation, the cultivated land is more likely to be converted to orchard land. Yantai Proper is a main production area of cherries and apples and with the increase of economic benefits, the cultivated land in the hilly area is more easily converted to orchard land.

The nearer to town center it is, the transition of cultivated land into orchard land will be easier. The peripheral region of town center is distributed with urban agriculture, and the regions along the water area with its convenient irrigation are also very important for the transition of cultivated land into orchard land. The more close to the pond, the more convenient the irrigation conditions are, cultivated land is also more easily converted to orchard. County roads and rural roads are the important factors for affecting the cultivated land into orchard land because of the convenient transportation conditions.

(4) Transition of cultivated land into other lands

Elevation, slope, cost distance to major water area and cost distance to minor water area are the main explanatory variables on the transition of cultivated land into other land use types. It means that with the increase of the slope and elevation, it will be easier for the transi- 
tion of cultivated land into other lands. With the increase of the elevation and slope of land, it will be more difficult to be used as cultivated land, especially for the steep area with the slope larger than $25^{\circ}$. The regression coefficients of cost distances to major water area and minor water area are negative, which means that, the nearer to water area it is, the easier for the transition of cultivated land into other land use types it will be, such as water area, grassland.

\section{Conclusions and Suggestions}

(1) We start our study on the driving mechanisms of cultivated land transition from quantitative view. We choose 11 explanatory variables which can be quantified from two aspects of natural geography and socioeconomic factors, and adopt the logistic regression equation to study the driving mechanisms of cultivated land transition. Our quantitative research is the very complement for former studies, and it is more intuitive and feasible to display relevant explanatory variables on cultivated land transition.

(2) The elevation factor has a significant influence on the transition of cultivated land into other land use types, and the regression coefficient is positive $(0.202)$. It has an ordinary effect on the transition of cultivated land into rural residential land and orchard land, and the regression coefficients are respectively 0.096 and 0.071 . The slope factor plays an important role in the transition of cultivated land into orchard land, rural residential land and other land use types, and the regression coefficients are respectively $-0.461,0.377$ and 0.444 . Factor of cost distance to major water area (lakes and rivers) has a significant correlation $(-0.461)$ on the transition of cultivated land into other land use types, and has an ordinary effect (1.676) on the transition of cultivated land into urban construction land. Factor of cost distance to minor water area (ponds) has a significant correlation on the transition of cultivated land into orchard land and other land use types, and the regression coefficients are respectively -0.480 and -0.874 , and has an ordinary effect $(-0.634)$ on the transition of cultivated land into rural residential land.

Factor of cost distance to district center and city expansion center have a significant influence on the transition of cultivated land into urban construction land, and the regression coefficients are respectively -2.301 and
-1.268 . Factor of cost distance to town center has a significant influence on the transition of cultivated land into urban construction land, rural residential land and orchard land, and the regression coefficients are respectively $-1.059,-0.221$ and -0.208 . Factor of cost distance to the city roads have a significant influence $(-0.847)$ on the transition of cultivated land into urban construction land. Factors of cost distance to county roads and cost distance to rural roads have a significant influence on the transition of cultivated land into rural residential land (the regression coefficients are respectively -0.428 and -0.614 ) and orchard land (the regression coefficients are respectively -0.451 and -0.326 ), and has an ordinary effect on the transition of cultivated land into other land use types (the regression coefficients are respectively 0.628 and 0.569 ).

(3) Study of Yantai Proper shows that, socioeconomic factors have the significant influence on the transition of cultivated land into urban construction land and rural residential land. Cost distance to district center is the dominant factor for the transition into urban construction land and factors of rural roads and county roads have an important affection on the location of the residential land expansion. Traffic and irrigation conditions have the significant influence on the location choice of the orchard land and natural factors (elevation, slope and distance to the water area) play an important role in the transition of cultivated land into other lands.

(4) As electro-mechanical wells are important in irrigation, we suggest adding the electro-mechanical wells to the factor of distance to minor water area. We also suggest that the effect of major roads including the national road, the highway and railway should be calculated respectively, because the effect of these factors on cultivated land transition is not continuous in space. In the next step of the study we would like to focus on the spatial layout model and quantitative methods on these three important factors. And owing to the lack of the quantitative method, no analysis of GDP and density of the people for cultivated land transition are conducted in this study, which will be a key point in the next research.

In addition, in the driving mechanism system of cultivated land transition, we should not only focus on the factors that can be qualified, but also focus on the factors that can not be qualified. We should also pay more attention to factors like policy and planning, which play an important role in the transition of cultivated land. 


\section{References}

Bai Wanqi, Zhang Yili, 2002. Role of traditional cultural factors in land use changes in the Qinghai-Tibet Plateau. Resources Science, 24(4): 11-15. (in Chinese)

Barbier E B, Burgess J C, Grainger A, 2010. The forest transition: towards a more comprehensive theoretical framework. Land Use Policy, 27(2): 98-107. doi: 10.1016/j.landusepol.2009. 02.001

Betts M G, Diamond A W, Forbes G J et al., 2006. The importance of spatial autocorrelation, extent and resolution in predicting forest bird occurrence. Ecological Modelling, 191(2): 197-224. doi: 10.1016/j.ecolmodel.2005.04.027

Cai Yunlong, Wang Yong, Li Yuping, 2009. Study on changing relationship of demand and supply of cultivated land in China. China Land Science, 23(3): 11-18, 31. (in Chinese)

Cao Yingui, Bai Zhongke, Zhou Wei et al., 2013. Forces driving changes in cultivated land and management countermeasures in the Three Gorges Reservoir Area, China. Journal of Mountain Science, 10(1): 149-162. doi: 10.1007/s11629-013-2240-5

Chen J F, Wei S Q, Chang K T et al., 2007. A comparative case study of cultivated land changes in Fujian and Taiwan. Land Use Policy, 24(2): 386-395. doi: 10.1016/j.landusepol.2006. 05.002

Chen Z, Lu C H, Fan L, 2012. Cultivated land changes and the driving forces in Yucheng, North China Plain. Journal of Geographical Sciences, 22(3): 563-573. doi: 10.1007/s11442-0120947-9

Chi V K, Van Rompaey A, Govers G et al., 2013. Land transitions in Northwest Vietnam: an integrated analysis of biophysical and socio-cultural factors. Human Ecology, 41(1): 37-50. doi: 10.1007/s10745-013- 9569-9

Crk T, Uriarte M, Corsi F et al., 2009. Forest recovery in a tropical landscape: What is the relative importance of biophysical, socioeconomic, and landscape variables? Landscape Ecology, 24(5): 629-642. doi: 10.1007/s10980-009- 9338-8

Ding C R, 2003. Land policy reform in China: Assessment and prospects. Land Use Policy, 20(2): 109-120. doi: 10.1016/ S0264-8377(02)00073-X

Dong Juan, Zang Shuying, 2011. Driving force mechanism of urban land use changes in Daqing city, Northeast China. Geographical Research, 30(6): 1121-1128. (in Chinese)

Gong Jianzhou, Liu Yansui, Chen Wenli, 2012. Optimal land use allocation of urban fringe in Guangzhou. Journal of Geographical Sciences, 22(1): 179-191. doi: 10.1007/s11442-0120920-7

Guan Wei, Wang Xue, 2009. Human dimensions of land use change in Dalian. Geographical Research, 28(4): 990-1000. (in Chinese)

He Yingbin, Chen Youqi, Yao Yanmin et al., 2009. Study on spatial characteristics of the relation between cultivated land non-agriculturalization and food production: a case study of the provinces in northeast China. Journal of Natural Resources, 24(3): 439-447. (in Chinese)
Kong Xiangbin, Zhang Fengrong, Xu Yan et al., 2003. Arable land change and its driving forces in intensive agricultural region: the case of Quzhou County of Hebei Province. Resources Science, 25(3): 57-63. (in Chinese)

Li Jinggang, He Chunyang, Shi Peijun et al., 2004. Change progress of cultivated land and its driving forces in northern China during 1983-2001. Acta Geographica Sinica, 59(2): 274-282. (in Chinese)

Li X M, Zhou W Q, Ouyang Z Y, 2013. Forty years of urban expansion in Beijing: what is the relative importance of physical, socioeconomic, and neighborhood factors? Applied Geography, 38: 1-10. doi: 10.1016/j.apgeog. 2012.11.004

Liang Youjia, Xu Zhongmin, Zhong Fanglei, 2008. Land use scenario analyses by based on system dynamic model and CLUE-S model at regional scale: a case study of Ganzhou District of Zhangye City. Geographical Research, 30(3): 564-576. (in Chinese)

Liu Jiyuan, Zhang Zengxiang, Xu Xinliang et al., 2009. Spatial patterns and driving forces of land use change in China in the early 21st century. Acta Geographica Sinica, 64(12): 1411-1420. (in Chinese)

Liu Qing, Chen Ligen, Zhang Fengrong, 2009. Econometric analysis of relationships between cultivated land conversion quantity and economic developments in China. Resources Science, 31(5): 787-793. (in Chinese)

Liu Xiaoping, Li Xia, Ai Bin et al., 2006. Multi-agent systems for simulating and planning land use development. Acta Geographica Sinica, 61(10): 1101-1112. (in Chinese)

Liu Yansui, Li Yurui, 2010. Spatio-temporal coupling relationship between cultivated land and agricultural labor changes at county level in China. Acta Geographica Sinica, 65(12): 1602-1612. (in Chinese)

Long Hualou, Liu Yansui, Li Xiubin et al., 2010. Building new countryside in China: a geographical perspective. Land Use Policy, 27(2): 457-470. doi: 10.1016/j.landusepol.2009.06.006

Long Hualou, Li Yurui, Liu Yansui et al., 2012. Accelerated restructuring in rural China fueled by 'ncreasing vs. decreasing balance' land-use policy for dealing with hollowed villages. Land Use Policy, 29(1): 11-22. doi: 10.1016/j.landusepol. 2011.04.003

Long Hualou, Tang Guoping, Li Xiubin et al., 2007. Socio-economic driving forces of land-use change in Kunshan, the Yangtze River Delta Economic Area of China. Journal of Environmental Management, 83(3): 351-364. doi: 10.1016/j. jenvman.2006.04.003

Ma Zhenling, Zeng Yongnian, Yan Li, 2012. Quantitative study on driving mechanism of land use and land cover change in Changsha-Zhuzhou-Xiangtan Urban Agglomerations. Bulletin of Surveying, 10: 41-44. (in Chinese)

Mao Jiangxing, Yan Xiaopei, Li Zhigang et al., 2009. A comprehensive research on the physical and human dimensions of land use changes under rapid urbanization in Shenzhen City. Journal of Natural Resources, 24(3): 523-535. (in Chinese)

Qiu Bingwen, Chen Chongcheng, 2008. Land use change simulation model based on MCDM and CA and its application. Acta 
Geographica Sinica, 63(2): 165-174. (in Chinese)

Qu Futian, Chen Jianglong, Chen Wen, 2005. Theoretical and empirical study on the land conversion economic driving forces. Journal of Natural Resources, 20(2): 231-241. (in Chinese)

Shi Peijun, Chen Jin, Pan Yaozhong, 2000. Land use change mechanism in Shenzhen City. Acta Geographica Sinica, 55(2): 151-160. (in Chinese)

Song X, Ouyang Z, Li Y et al., 2012. Cultivated land use change in China, 1999-2007: policy development perspectives. Journal of Geographical Sciences, 22(6): 1061-1078. doi: 10.1007/s11442-012-0983-5

Xie Hualin, Li Bo, 2008. Driving forces analysis of land-use pattern changes based on logistic regression model in the farming-pastoral zone: a case study of Ongiud Banner, Inner Mongolia. Geographical Research, 27(2): 294-304. (in Chinese)

Yan Xiaopei, Mao Jiangxing, Pu Jun, 2006. Research on the human dimensions of land use changes in the Mega-Urban Region: A case study of the Pearl River Delta. Acta Geographica Sinica, 61(6): 613-623. (in Chinese)

Yang Ren, Liu Yansui, Chen Yufu et al., 2013. The remote sensing inversion for spatial and temporal changes of multiple cropping index and detection for influencing factors Around Bohai Rim in China. Scientia Geographica Sinica, 33(5): 588-593. (in Chinese)

Ye Changsheng, Dong Yuxiang, 2011. Fractal analysis of land use in Zhujiang River Delta. Transactions of the Chinese Society of Agricultural Engineering, 27(4): 330-335. (in Chinese)

$\mathrm{Yu} \mathrm{B}, \mathrm{Lu} \mathrm{C}, 2006$. Change of cultivated land and its implications on food security in China, Chinese Geographical Science, 16(4): 299-305. doi: 10.1007/s11769-006-0299-4

Yu Linjun, Sun Danfeng, Peng Zhongren et al., 2013. A cellular automata land use model based on localized transition rules. Geographical Research, 32(2): 671-682. (in Chinese)

Zhang Guoping, Liu Jiyuan, Zhang Zengxiang, 2003. Spatial-temporal changes of cropland in China for the past ten years based on remote sensing. Acta Geographica Sinica, 58(3): 323-332. (in Chinese)

Zhu Huiyi, He Shujin, Zhang Ming, 2001a. Driving forces analysis of land use change in Bohai Rim. Geographical Research, 20(6): 670-678. (in Chinese)

Zhu Huiyi, Li Xiubin, He Shujin et al., 2001b. Spatio-temporal change of land use in Bohai Rim. Acta Geographica Sinica, 56(3): 253-260. (in Chinese) 